\title{
An Optimized Power Conversion System Concept of the Integral, Inherently-Safe Light Water Reactor
}

\author{
Matthew J Memmott ${ }^{1}$, Paul R. Wilding ${ }^{1}$, Bojan Petrovic ${ }^{2}$
}

1. Brigham Young University, 350 Clyde Building, Provo UT, 84602, 801-422-6237, memmott@ byu.edu

2. Georgia Institute of Technology, 770 State Street, Atlanta, GA 30332

Abstract - The integral, inherently safe light water reactor (I ${ }^{2} S$-LWR) has been developed to significantly enhance passive safety capabilities while maintaining cost competitiveness relative to the current light water reactor ( $L W R$ ) fleet. The compact heat exchangers of the $I^{2} S$ - LWR preclude boiling of the secondary fluid, which decreases the probability of heat exchanger failure, but this requires the addition of a flash drum, which negatively affects the overall plant thermodynamic efficiency. A state of the art Rankine cycle is proposed for the $I^{2} S$-LWR to increase the thermodynamic efficiency by utilizing a flash drum with optimized operational parameters. In presenting this option for power conversion in the $I^{2} S$ LWR power plant, the key metric used in rating the performance is the overall net thermodynamic efficiency of the cycle. In evaluating the flash-Rankine cycle, three basic industrial concepts are evaluated, one without an intermediate pressure turbine, one with an intermediate turbine and one reheat stream, and one with an intermediate turbine and two reheat streams. For each configuration, $a$ single-path multi-variable optimization is undertaken to maximize the thermal efficiency. The third configuration with an intermediate turbine and 2 reheat streams is the most effective concept, with an optimized efficiency of $35.7 \%$.

\section{Keywords: I2S-LWR; Steam Generation System; Multivariable Optimization; Flash Rankine Cycle}

\section{Introduction}

The integral, inherently safe light water reactor $\left(I^{2} S-L W R\right)$ has been developed to significantly enhance passive safety capabilities while maintaining cost competitiveness relative to the current light water reactor (LWR) fleet. These capabilities are made possible through several key safety features that serve to both decrease accident frequency and mitigate accident consequences through passive safety technology. The most significant of these safety features includes the decay heat removal system, the core makeup tanks, and the compact heat exchanger. Each of these systems has innovative design aspects that improve overall plant safety. However, the incorporation of these systems within nuclear power plants has the potential to negatively impact plant economic performance, manifested primarily in alterations to manufacturing, maintenance, and operational methods ${ }^{1}$. This is seen clearly in the compact heat exchanger design utilized in the $I^{2} S-L W R$. As part of the safe operation of this compact heat exchanger, secondary coolant is pressurized to preclude boiling, which decreases the probability of heat exchanger failure, but this requires further processing, which negatively affects the overall plant thermodynamic efficiency ${ }^{2}$. Thus, it is of interest to develop a power conversion system (PCS) that meets the requirement of no boiling in the primary heat exchanger while maximizing the thermodynamic efficiency of the overall plant.

In order to offset the negative economic impacts of incorporating passive safety systems, significant focus has been placed on maximizing the thermodynamic efficiency of the I'S-LWR through modifications or alterations to the PCS. The initial I'S-LWR PCS design, which was based on a simple Rankine cycle, was able to achieve an efficiency of $33 \%{ }^{2}$. However, this value is on the lower end of the 
thermodynamic performance spectrum for current nuclear plants, and there is no margin should future alterations in the reactor design further decrease the efficiency.

A state of the art Rankine cycle is proposed for the I'S-LWR to increase the thermodynamic efficiency. The cycle utilizes a flash drum with optimized operational parameters, which represents the base PCS for the $I^{2} S-L W R$. This is the base configuration for the I'S-LWR primarily because it represents standard, well-known technology, with no deviances in fabrication, maintenance, or operating procedures.

This paper describes the optimization of the base configuration PCS for the $I^{2} S-L W R$, which is designed to maximize the economic viability of the plant. In presenting this Rankine cycle option for power conversion in the $I^{2} S$-LWR power plant, the key metric used in rating the performance is the overall net thermodynamic efficiency of the cycle. Thus, the primary purpose in optimizing the PCS design is the maximization of the overall thermodynamic efficiency of the cycle.

\section{Power Conversion System Performance}

The thermodynamic efficiency is the predominant metric that is used to evaluate the effectiveness of a given PCS. The thermodynamic efficiency is a measure of electrical power output relative to the thermal power input for a PCS, and thus indicates the effectiveness of converting thermal energy to electrical energy. The net thermodynamic efficiency represents the thermodynamic efficiency after house loads such as pumps are considered. Currently operating nuclear power stations have efficiencies ranging from $33 \%$ to $37 \%^{3}$, and thus any commercially viable plant should maintain a net thermodynamic efficiency of at least $33 \%$. Several studies have been dedicated to achieving even marginal increases in thermodynamic efficiencies $s^{4,5,6,7,8}$. This is because the thermodynamic efficiency of a cycle correlates directly to the economic competitiveness of the power-plant in which it is integrated. Based on simple calculations, for a currently operating nuclear power plant with a $35 \%$ thermodynamic efficiency, a $1 \%$ increase in the thermodynamic efficiency could translate into at least a $\$ 40 \mathrm{M}$ increase in annual profits for the plant.

In addition to indicating power plant economic performance, the thermodynamic efficiency is an extremely useful metric that allows the performance of various power generation systems to be easily compared and contrasted with respect to fuel utilization. Therefore, this metric will be utilized as the primary basis for comparison regarding the Rankine cycle design options for generating electricity with the $I^{2} S$-LWR. As stated by the $I^{2} S-L W R$ design team ${ }^{9}$, one of the primary design basis goals was to design a PCS that is capable of reaching thermodynamic efficiencies of greater than $33 \%$. In addition, a stretchgoal of $36 \%$ was established to further enhance economics; at this efficiency, the economics of the $I^{2} S$ LWR would be comparable to efficiencies that one would see in current Gen II or Gen III light water reactor power conversion systems ${ }^{9,10}$.

For each Rankine cycle design option introduced in this paper, dozens of design, performance, and state variables can be altered which modify the thermodynamic efficiency. Therefore, a simple, singleapproach multivariable sensitivity analysis was conducted for the key variables that impact the thermodynamic efficiency of the overall cycle. The optimum thermodynamic efficiency based on these sensitivity studies was used to compare the flash drum Rankine cycle design options, such that each efficiency reported here indicates the idealized efficiency for the given thermodynamic power conversion system design. 


\section{Additional PCS Considerations}

In addition to thermodynamic efficiency, there are other performance metrics that should be considered in selecting a given power conversion system for use with the $I^{2} S-L W R$. These performance metrics include:

1. Capital Costs

2. Operations and Maintenance

3. Safety

The capital costs of a PCS are the first significant metric that must be considered in the system design in addition to the thermodynamic efficiency. Thermodynamic efficiency can be asymptotically increased by increasing the turbine stages, reheaters, exchangers, and other complex components. However, the marginal increase in efficiency decreases with each subsequent component added to the system, and there exists a point at which the increased capital cost incurred by adding an additional component cannot be offset by the lifetime net profit increase provided by that component. In other words, the return on investment for the added component is greater than the life of the plant, and thus is an unwise investment. Further, first of a kind concepts have large uncertainties associated with capital cost relative to performance. Thus, this metric precluded the use of exotic and largely unproven power cycles with the I'S-LWR concept.

The cost of operation and maintenance (O\&M) components and systems within a PCS must also be considered, in order to ensure that the increase in profit realized from thermodynamic efficiency increases is not parasitically consumed in additional O\&M costs. Changes in steady state flow rates or heat requirements, water chemistry maintenance, or corrosion susceptibility are some of the many factors that are considered in determining changes to the O\&M costs. For the $I^{2} S-L W R$, this metric precluded the use of highly expensive and specialized equipment for individual components in the $I^{2} S$ LWR. Thus, proven technology components such as the flash drum, even if novel in utilization, were selected whenever possible over untested components and systems to simplify operation and maintenance.

Finally, the safety of a nuclear power plant is the highest priority and consideration in any design effort. In order to successfully implement an alternative power conversion system, it must be verified that the impact on the safety performance of the reactor is negligible or in the direction of improved safety. If this is not true, then significant licensing risk must be assumed in order to adopt the new technology. As this course of action represents high costs and low probabilities of success, the I'S-LWR power conversion system must not contribute any negative factors to the safety of the plant. Thus, parallel to the optimization studies conducted here, safety analyses for the power conversion system are being conducted to determine the impact to nuclear plant safety. A full plant model was developed to investigate the safety of the I'S-LWR using the base design. These studies consist of the development of a full plant model for each of the power conversion systems proposed in this paper, and the implementation of a series of abnormal operational transients. The results of these transients are then compared and contrasted to each other and to similar transients analyzed for current plants. Any situations where safety impacts are introduced due to the power conversion system implementation are carefully considered, and design alterations or solutions are proposed in order to prevent such an impact to the safety of the I'S-LWR. 


\section{Optimized Rankine Cycle}

The concept explored in this paper is an industrial quality modified Rankine cycle ${ }^{7}$ with optimized operation parameters. This concept, which is depicted in Figure 1, consists of microchannel heat exchangers $^{2}(\mathrm{MCHX})$ which consist of millimeter scale flow channels etched in metal plates that are stacked vertically at alternating orientations to facilitate hot and cold flow through the channels. The primary role of the $\mathrm{MCHX}$ is to transfer heat from the primary loop to the power conversion system followed by flash drums which generate steam that is sent to the turbomachinery. This steam is then expanded in a high pressure turbine, and the turbine effluent is then sent to a moisture separator. The separated fluid is collected and used to heat the overall cycle condensate in a series of feedwater heaters, while the steam is sent to a reheater where a portion of unexpanded steam drawn off the high pressure turbine is used to increase the temperature of the steam from the moisture separator. This reheated steam is then sent to an intermediate turbine, which operates similarly to the high pressure turbine including moisture separation and reheat. Finally, a series of three low pressure turbines is used for the final steam expansion, after which the condensate is sent to a condenser unit. The condensate is then directed to a series of feedwater heaters, and then is combined with the moisture streams from the turbine moisture separators. This heated water is then combined with flash drum liquid effluent, and this combined fluid is sent to the primary heat exchanger for reheating.

In integrating an industriallycertified Rankine cycle power

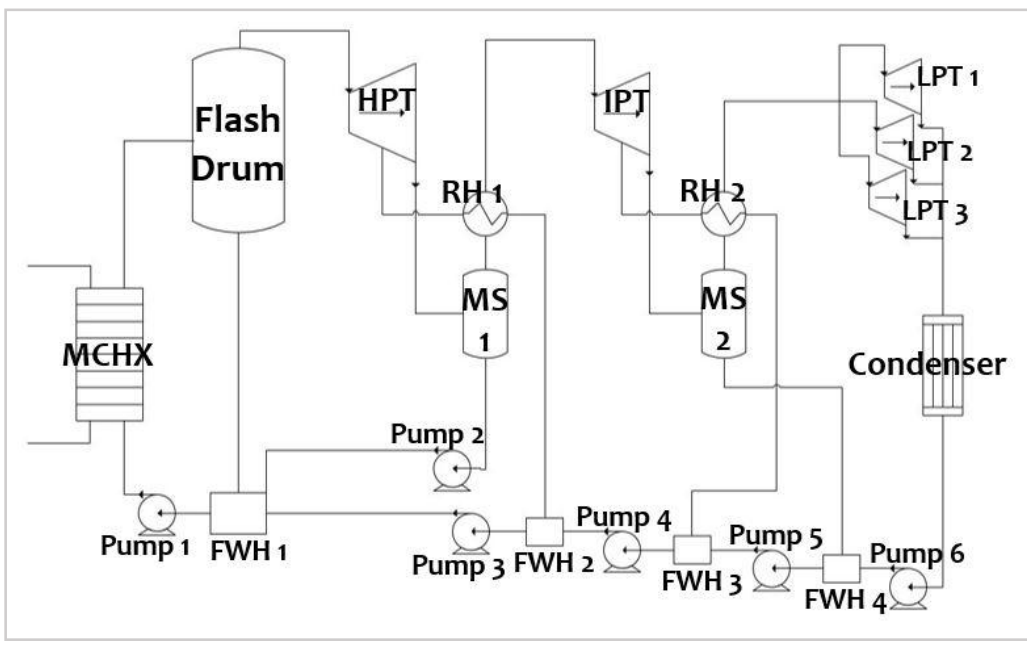

Figure 1: PFD of Case Design 2b conversion system with the $I^{2} S$ LWR, there are dozens of variables that contribute to the thermodynamic efficiency of the power conversion system. These include coolant temperatures and pressures, flow rates, pumps, reheaters, and valves. Thus, an optimization study was conducted to determine the best configuration for the Rankine cycle integrated with the $I^{2} S$-LWR and a flash drum. Additional equipment can continually be added to the system to provide incrementally smaller gains to the thermodynamic efficiency of the power conversion system; however, there comes a point when increased thermodynamic efficiency cannot offset the capital cost of the additional equipment purchased. As such, the following sections detail the thermodynamic optimization of the base Rankine cycle power conversion system using industrial standard configurations.

There are three commonly used configurations for industrial Rankine cycle applications, each requiring varying amounts of equipment. The first case (case 1 ) is the simplest, with only two distinct turbine types stages, as seen in Figure 2. This cycle option has the lowest thermodynamic efficiency, but it conversely has the lowest capital cost requirements. The second case (case $2 a$ ) is similar but introduces an intermediate pressure (IP) turbine, as seen in Figure 3. The third case (case 2 b) is almost identical to 
case $2 \mathrm{a}$ but has the potential for the highest thermodynamic efficiency with a similarly increased capital cost (see Figure 4).

Case 1 includes a HP steam turbine and three LP steam turbines. Immediately after vaporization in the flash drum, the steam is sent to and expanded in the HP steam turbine. The liquid phase effluent from the flash drum is recombined with the turbine condensate from the feedwater heaters and enters the MCHX once again. Within the HP steam turbine, a portion of the unexpanded steam is withdrawn from the turbine, as represented by the red line in Figure 2. This stream is run through a heat exchanger downstream of the turbine in order to reheat HP turbine effluent before entering the LP steam turbines. As the unexpanded steam heats the HP turbine effluent, it condenses and is joined, via

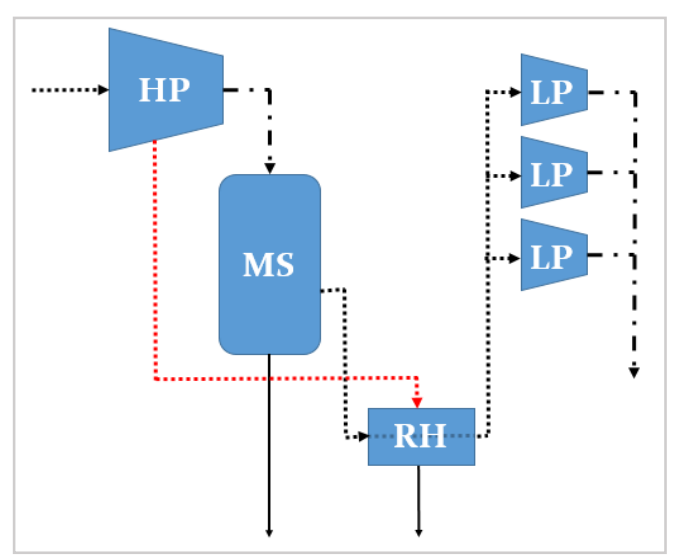

Figure 2: Design for Case 1 an open feedwater heater, with the rest of the condenser liquid stream returning to the MCHX. The steam that expands in the HP steam turbine contains some condensed water (less than $12 \%$ by mass), and this turbine condensate can either be removed in-situ or in a moisture separator immediately following the turbine. The saturated steam from the moisture separated is then passed to the reheater heat exchanger, where it is reheated by the unexpanded steam stream removed from the HP turbine and is then sent through the LP steam turbines.

It is of interest to note that the turbine blade length is related to the pressure and flow rate of the incoming steam. Thus, for lower pressure steam, longer turbine blades are required. For the steam flow rates and pressures required in the I'S-LWR power conversion system LP steam turbines, three separate turbines are required. This is because trying to consolidate all the flow in a single turbine would result in blades so long that cracking and blade fracture during regular operation would be highly likely. Additionally, several smaller turbines are cheaper than a single large one. For this reason, the PCS designs in this study use three LP steam turbines in parallel. The remaining steam that is not condensed in the LP turbines is condensed in the condenser, which is another heat exchanger that uses cold utility water to induce a phase change in the saturated steam (see Figure 1). The condensate effluent is then combined with the liquid streams from the moisture separator and the steam reheater through a series of flow junctions and open feedwater heaters. This fluid is then pumped through the recirculation pump, where it is pressurized to the primary heat exchanger pressure of 120 bar. This high pressure water is then directed through the primary heat exchanger where it is heated, and then flashed to steam in the flash drum to complete the cycle.

Case $2 \mathrm{a}$ is similar in construction to the first case design, however it includes an IP steam turbine (see Figure 3).

Therefore, there is a second moisture separator and reheater immediately after the IP turbine. In this case, the steam drawn prior to full expansion from the HP steam turbine is used to reheat the fully expanded steam in both

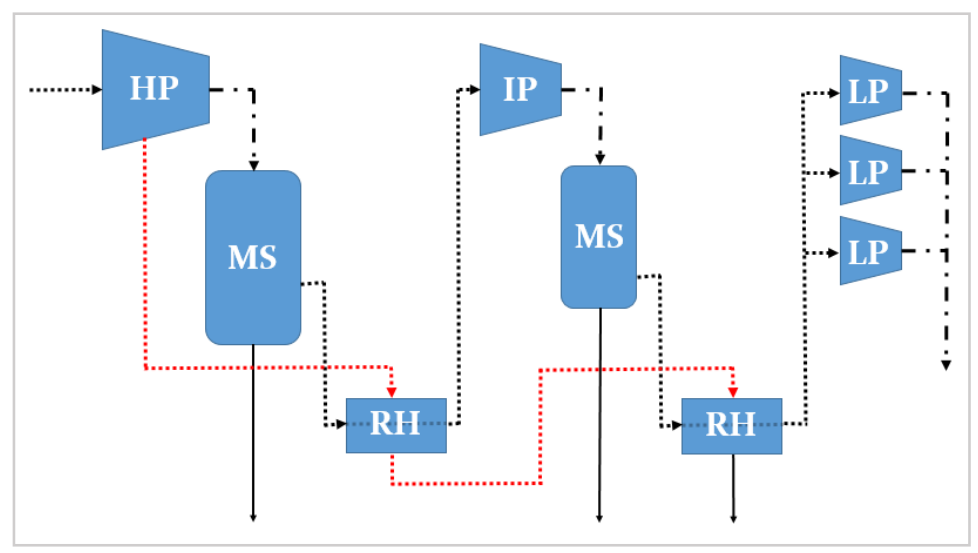

Figure 3: Design for Case $2 a$ 
reheaters in series. The first reheater heats up the steam bound for the IP steam turbine. The second heats up the steam bound for the LP steam turbines. After the reheating stream condenses completely in the second reheater, it is sent to an open feedwater heater (as is done in case 1) to join the rest of the liquid returning to the MCHX. Everything else about this case design is the same as the first case.

Case $2 \mathrm{~b}$ has a similar design as case $2 \mathrm{a}$. The primary difference is that the stream taken from the HP turbine is used only in the first reheater (see Figure 4) while an additional stream of unexpanded steam is drawn from the IP steam turbine to act as the hot stream in the second reheater. Each reheating stream is condensed the in the respective reheater heat exchanger and then is combined with the rest of the liquid water condensate from the condenser via their respective open

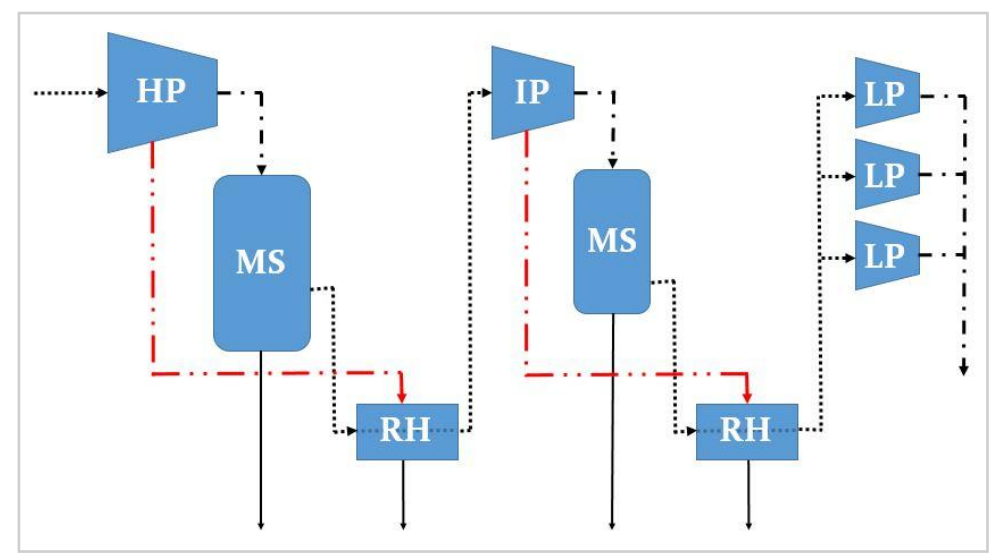

Figure 4: Design for Case $2 b$ feedwater heater.

Each of the case designs $2 a$ and $2 b$ require additional feedwater heaters and pumps in the chain of equipment leading back to the MCHX. In case $2 a$, one additional feedwater heater and pump is required, while in case $2 b$ two additional feedwater heaters and pumps are required. In case $2 b$, these additional pieces of equipment are needed because of the additional condensate streams from the second moisture separator and reheater that need to join the rest of the liquid water returning to the MCHX (see Figure 1).

The reason for including the reheaters in these three case designs is that each heater increases the energy of the working fluid and will thus increase the overall thermodynamic efficiency of the PCS. This concept is illustrated in the T-S diagram in Figure 5. Here, line 1-2 represents the heating done by the $\mathrm{MCHX}$. The drop immediately following point 2 is the flash drum. Point 3 illustrates the thermodynamic state of the saturated steam leaving the top of the flash drum. The drop after point 3 is the HP steam turbine, and point 4 is the steam leaving the moisture separator. In a simple Rankine cycle without reheat, the stream would then enter the next steam turbine, dropping from point 4. However, a reheater exchanger included between the turbines increases the temperature of the working steam to point 5 before it goes through the next turbine. The additional area under the curve represents additional energy derived in the process for the same energy input, and thus represents an additional overall efficiency for the cycle. The expectation is that this added area under the curve will provide an increase in

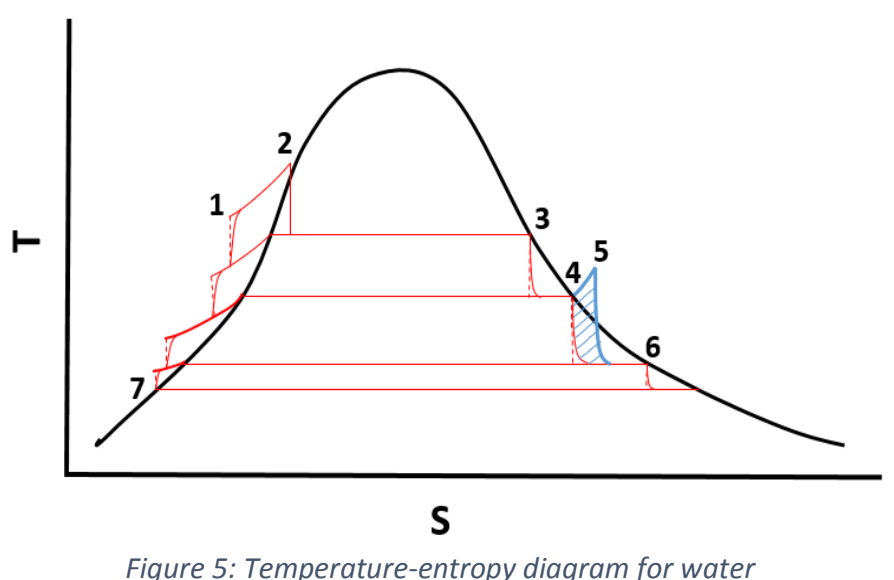

Figure 5: Temperature-entropy diagram for water 
energy that more than compensates for the loss associated with removing a portion of the steam prior to full expansion to provide reheating. Point 6 represents the saturated steam leaving the second moisture separator, and point 7 is immediately following the condenser and before any of the pumps or open feedwater heaters.

\section{Optimization}

The goal for this case study was to optimize these three case designs using a single change multivariable analysis methodology. Three iterations of sensitivity analyses were performed for several key design parameters. Each iteration consisted of choosing base values for the design parameters and running a sensitivity analysis for each one individually. Each sensitivity analysis consisted of holding all design parameters at their respective base values while changing only one of them. Based on the results, new base values for the design parameters were chosen for the next iteration of sensitivity analyses. The figure of merit used to decide on the next set of base values for the design parameters was the maximization of the overall thermodynamic efficiency of the PCS. Thus, with each iteration, the efficiency increased. The first two iterations of analyses assumed that the maximum temperature coming out of the $\mathrm{MCHX}$ was at $319^{\circ} \mathrm{C}$. The third iteration of analyses for each case increased that temperature to $321^{\circ} \mathrm{C}$ in order to see the impact of the $\mathrm{MCHX}$ outlet temperature on the thermodynamic efficiency.

An existing interface between Excel's VBA and ChemCAD was used to obtain the data for these sensitivity analyses. Chemstrations, the creators of ChemCAD, provided this interface via an Excel file named VBClient.xIs. Additional code was written in Visual Basic (VBA) to procedurally adjust the design parameters in ChemCAD and evaluate the corresponding thermodynamic efficiency.

If an overall thermodynamic efficiency of $35 \%$ is assumed for the PCS, then for a $1000 \mathrm{MW}_{\mathrm{e}}$ power plant, $2850 \mathrm{MW}_{\text {th }}$ must be produced in the core and transferred through the MCHX. There are four MCHX and subsequent PCS loops in the RPV, each with its own flash drum and turbine/reheater systems.

Therefore, each PCS loop was assumed to be receiving one-fourth of the total generated $2850 \mathrm{MW}_{\mathrm{th}}$. For each variation of parameters, a different overall water flow rate was provided in each loop so as to keep the heat duty of the MCHX at exactly $712.5 \mathrm{MW}$. A simple root-finding algorithm was used to find the overall flow rate that would result in a $\mathrm{MCHX}$ heat duty of $712.5 \mathrm{MW}$ for every variation of the design parameters.

The overall net thermodynamic efficiency was calculated by adding up the work obtained from all turbines, subtracting from it the work put in to running all pumps, and dividing it by the heat duty of the $\mathrm{MCHX}$, which is $712.5 \mathrm{MW}$ (see Equation 1). In each case, the pump overall efficiency is assumed to be $85 \%$ while the turbine overall efficiency is assumed to be $91.5 \%$. These are common and quite achievable values for turbomachinery ${ }^{10,11}$, and are used as a reference efficiency point for this study. In reality, as the flow conditions change, these efficiencies would also change for a given pump or turbine. However, for the purposes of this paper, the constant efficiencies are maintained by assuming a different pump/turbine design is used when different flow conditions are encountered through the optimization. The new turbomachinery design is assumed to have the same efficiency as the previous design, albeit at the new flow conditions. The pumps and turbines for the final, fully-optimized PCS design will be selected to operate at these efficiencies at steady-state. The overall thermodynamic efficiency $(\eta)$ can be found using: 


$$
\eta=\frac{W_{\text {turbines }}-W_{\text {pumps }}}{Q_{M C H X}}
$$

where $\mathrm{W}_{\text {turbines }}$ is the total work derived by the steam turbines, $\mathrm{W}_{\text {pumps }}$ is the total power of the PCS pumps, and $\mathrm{Q}_{\mathrm{MCHX}}$ is the total energy supplied by the MCHX.

\section{V.a. Case 1}

Six variables were chosen for analysis for case 1, seen in Figure 6. In order to understand how the flash drum could best be used, one of the parameters was the pressure of the stream entering the flash drum, $P_{i n}$, and another is the pressure inside the flash drum, $P_{0}$. To verify the effectiveness of drawing steam from the HP steam turbine to use for reheating, the flow rate fraction and pressure of the drawn steam, $m_{1 v}$ and $P_{1 v}$ respectively, were also analyzed. $P_{1}$ is the outlet pressure for the HP steam turbine. $P_{3}$ is the outlet pressure for the LP steam turbines and was chosen only to verify that the overall thermodynamic efficiency will peak when $P_{3}$ is the lowest it can realistically be.

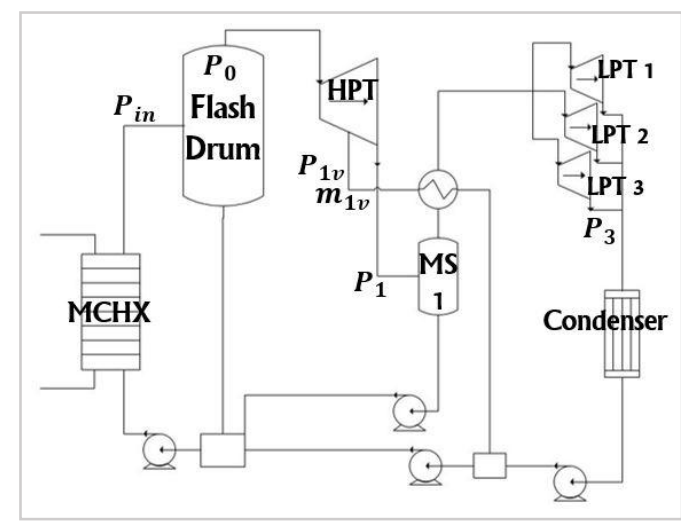

Figure 6: Parameters analyzed for Case 1

During each sensitivity analysis pertaining to the first iteration, one of these six parameters was varied while the other five were held constant at their base values. Those base values in addition to their tested variances were chosen via an educated guess and are found in Table 1Error! Reference source not found..

Table 1: Base values for tested design variables in Case 1

\begin{tabular}{|c|c|c|c|c|}
\hline Parameter & $\mathbf{1}^{\text {st }}$ Iteration & $\mathbf{2}^{\text {nd }}$ Iteration & $\mathbf{3}^{\text {rd }}$ Iteration & Units \\
\hline $\mathrm{m}_{1 \mathrm{v}}$ & 0.19 & 0.19 & 0.19 & \\
\hline $\mathrm{P}_{1 \mathrm{v}}$ & 20 & 10 & 10 & bar \\
\hline $\mathrm{P}_{1}$ & 5 & 6.6 & 6.6 & bar \\
\hline $\mathrm{P}_{3}$ & 0.086 & 0.086 & 0.086 & bar \\
\hline $\mathrm{P}_{\text {in }}$ & 150 & 120 & 123 & bar \\
\hline $\mathrm{P}_{0}$ & 84 & 90 & 90 & bar \\
\hline
\end{tabular}

Several limitations to the parameter values were determined based on engineering judgment. For example, the fractional flow rate of unexpanded steam diverted to the first reheater, $m_{1 v}$, was capped at a value of 0.19 , because at fractions of 0.3 and higher the reheating steam was not condensed completely in the reheater and thus entered the pumps, potentially damaging them. The pressure 
leaving the LP steam turbines, $P_{3}$, was only dropped to 0.086 bar, as this value represents the lower end of the normal outlet pressure for current industrial steam turbines.

The sensitivity parameters were also adjusted to preclude boiling in the MCHX channels. The pressure inside the $\mathrm{MCHX}$ that enters the flash drum, $P_{\text {in }}$, was not tested below 120 bar during the second iteration. At 120 bar and $319^{\circ} \mathrm{C}$, the water would be approximately $5^{\circ} \mathrm{C}$ below its boiling point. This temperature difference serves as a buffer against any of the water vaporizing inside the flow channels of the $\mathrm{MCHX}$. The third iteration for each case was run assuming the temperature leaving the MCHX to be $321^{\circ} \mathrm{C}$. In these analyses, the lowest allowable pressure at this point is $123 \mathrm{bar}$.

Figure 7 shows the three sensitivity analyses done with respect to $m_{1 v}$. The first iteration, shows a slight

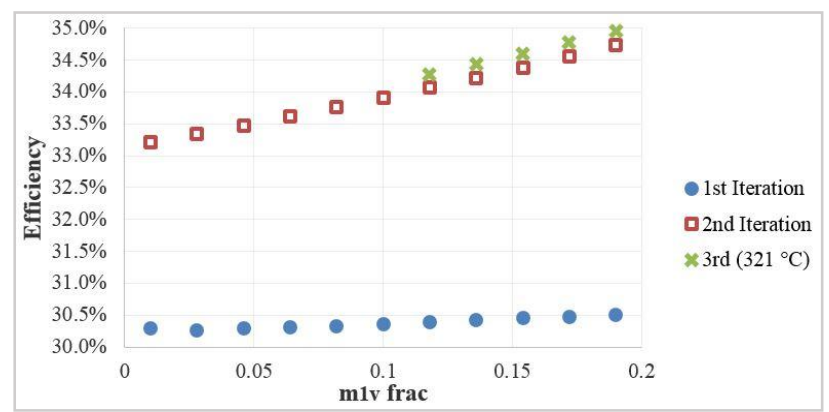

Figure 7: Efficiency vs. m1v for Case 1

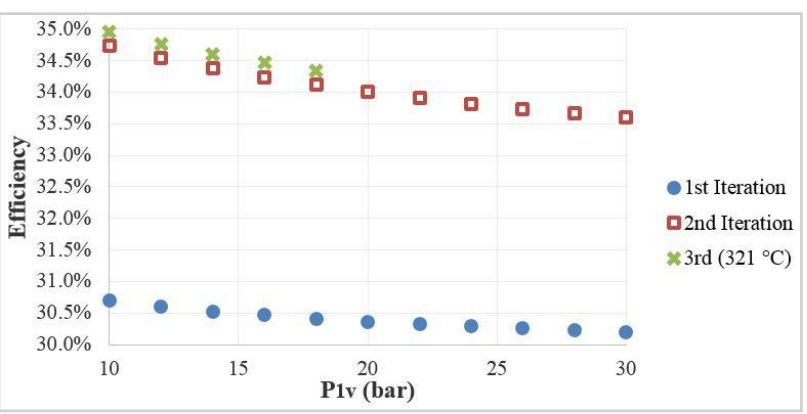

Figure 8: Efficiency vs. P1v for Case 1

increase in efficiency with an increase in flow rate fraction. This trend was amplified during the second

and third iterations. The increase in efficiency when stepping from the first iteration to the second is due to the change in base values for the other design parameters, or in other words is explained by an approach to the optimal values of the other process parameters. These values are presented in Table 1Error! Reference source not found.. Fewer data points were taken for the third iteration, because its main purpose was to demonstrate that the general trends held true even when the temperature into the flash drum increased to $321^{\circ} \mathrm{C}$. Figure 8 shows that with decreasing $P_{1 v}$ of the drawn reheating stream, efficiency increases. For this reason, a value of 10 bar was chosen as the base value for the second and third iterations.

Figure 9 shows the tendency for efficiency to rise with increasing $P_{1}$ coming out of the HP steam turbine. During the first iteration, there was a peak in efficiency at 6.6 bar. This was made the base value in the subsequent iterations. In the second and third iterations, however, there were no peaks. The data points above 8 bar spike in efficiency, because the $10^{\circ} \mathrm{C}$ approach temperature in the reheater was violated. This happened because during the second and third iterations, $P_{1 v}$ was dropped to $10 \mathrm{bar}$. This caused the temperature of the reheating stream to drop closer to that of the stream being reheated. A pinch point was reached in the reheater, the reheating steam did not all condense, vapor entered the system pumps, and the iterative algorithm for finding the mass flow rate converged on a higher-than-actual

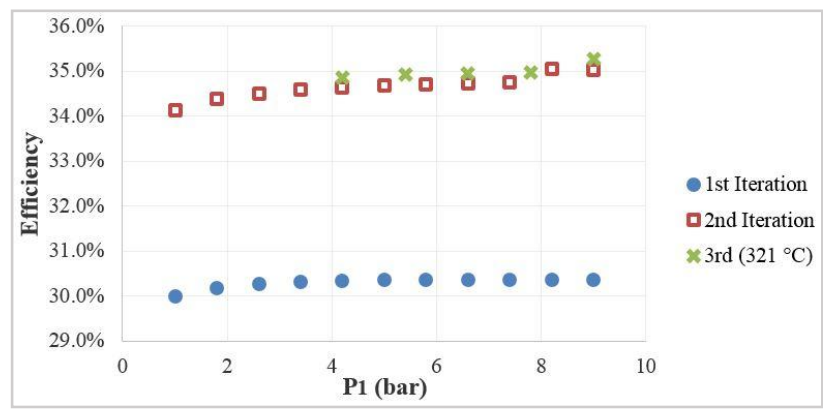

Figure 10: Efficiency vs. P1 for Case 1

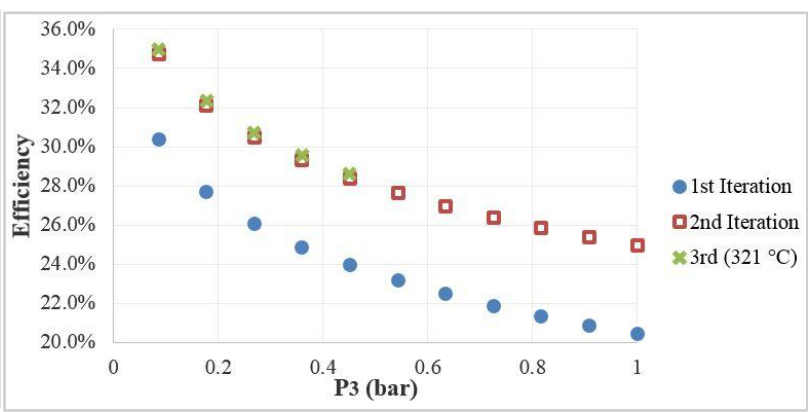

Figure 9: Efficiency vs. P3 for Case 1 
flow rate. These higher efficiency points above 8 bar are not accurate, and thus cannot be utilized as reliable data. Therefore, 6.6 bar is a safer value for operation because it is sufficiently below the pinch point.

Figure 10 shows the results of raising the outlet pressure of the LP steam turbines, $P_{3}$. Because dropping the back pressure of the turbine (at a constant inlet pressure) represents extracting greater amounts of energy, it is no surprise that raising the outlet pressure lowers the overall thermodynamic efficiency of the cycle.

A more thorough sensitivity analysis was done on the pressures in and out of the flash drum in order to learn more about the behavior of water as it vaporizes at such high pressures. Figures Figure 11, Figure 12 , and Figure 13 show the results of the analyses for the first, second, and third iterations, respectively. The first iteration revealed higher overall efficiencies when $P_{\text {in }}$ was at its lowest allowable value of 120 bar and peaked at a $P_{0}$ of 90 bar and an efficiency of $33.5009 \%$. The highest efficiency seen in iteration 3 was $34.97 \%$, with a $P_{\text {in }}$ of 123 bar and a $P_{0}$ of 92 bar.

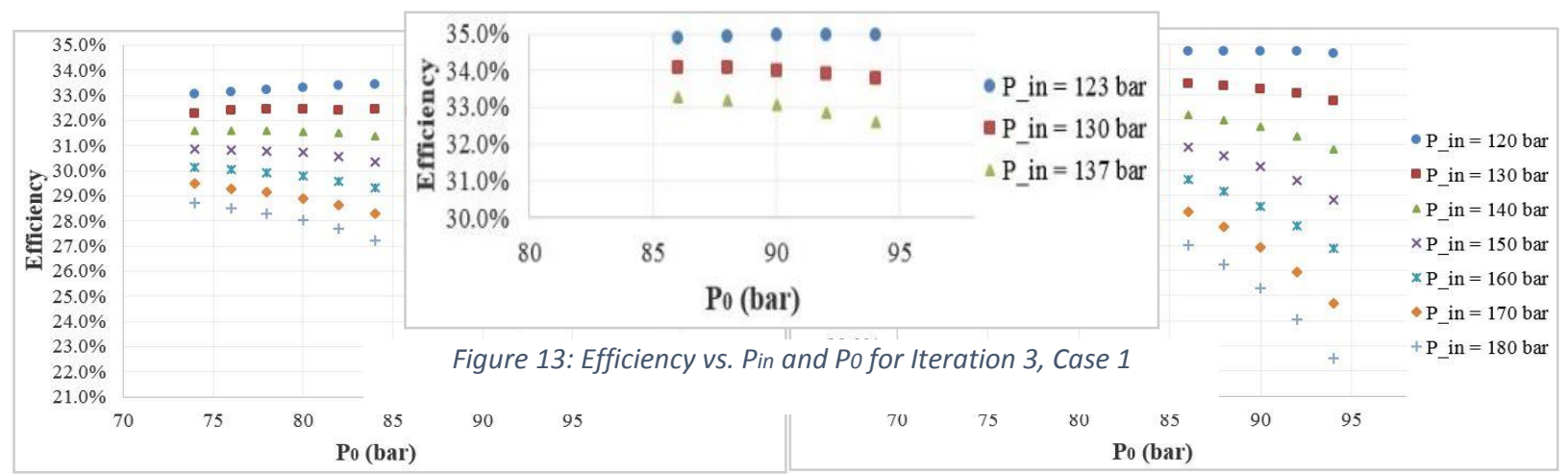

Figure 11: Efficiency vs. Pin and Po for Iteration 1, Case $1 \quad$ Figure 12: Efficiency vs. Pin and Po for Iteration 2, Case 1

The pressure differential across the flash drum during the first iteration was 66 bar. The peak efficiency achieved in case 1, however, took place with a pressure drop of only 30 bar. It is initially unclear why a smaller pressure drop would produce a higher vapor fraction in the flash drum, as flashing analyses under other conditions do not follow this trend. However, a brief analysis of a P-H diagram is helpful in understanding this counterintuitive phenomenon. 
Figure 14 shows the $\mathrm{P}-\mathrm{H}$ diagram for water in the pressure/enthalpy ranges of interest. The blue line represents the isotherm at $319^{\circ} \mathrm{C}$, the yellow line represents the pressure inside the flash drum where $P_{0}$ is $84 \mathrm{bar}$, and the orange lines (from top left to right) represent the inlet pressures 180, 150, and 120 bar, respectively. As can be seen in the figure, due to the proximity to the critical point, the isotherm has a negative slope at the point of operation, indicating that larger pressure drops decrease vapor production inside the flash drum. This is illustrated through the use of the orange line depicting the pressure drop from 120 bar. One can see that this line intersects the yellow line furthest to the right.

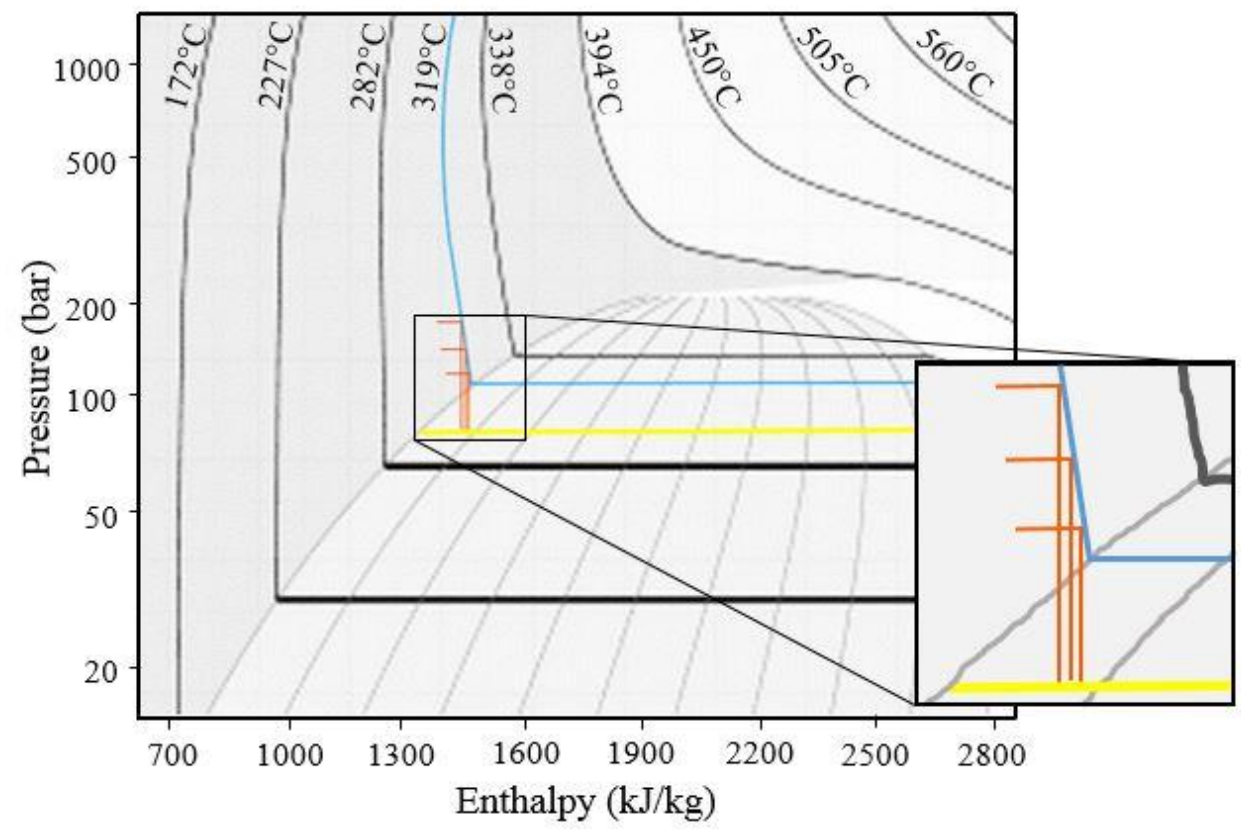

Figure 14: P-H diagram for water, showing Pin and PO for flash drum

When utilizing the lever rule, one can clearly see that this illustrates that lower pressure drops generate more vapor than the higher pressure drops in this region. This increase in steam generation provides more energy to be obtained via the steam turbines. Thus, the overall thermodynamic efficiency was highest when $P_{\text {in }}$ was 120 bar.

\section{v. b. Case $2 \mathrm{a}$}

In the sensitivity analyses for case design $2 a$, five of the same parameters were investigated, including $P_{i n}, P_{0}, m_{1 v}, P_{1 v}$, and $P_{1}$. The outlet pressure of the LP steam turbines was omitted because the results for case 1 illustrate that it is most efficient to keep $P_{3}$ at 0.086 bar. The sixth parameter analyzed for case $2 \mathrm{a}$ was instead the outlet pressure of the IP steam turbine, $P_{2}$ (see Figure 15).

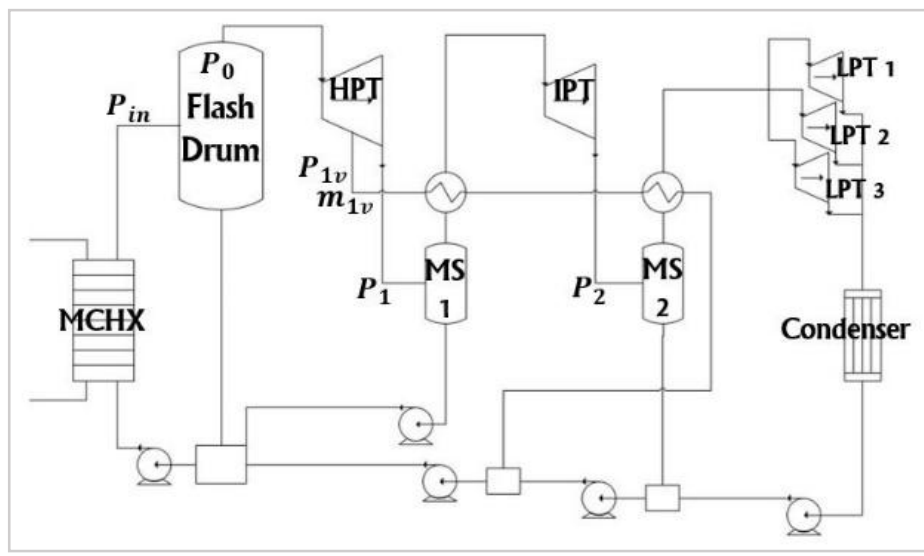

Figure 15: Parameters analyzed for Case $2 a$

The base values for these six parameters during the sensitivity analyses are found in Table 2Error! Reference source not found.. The starting 
values for the first iteration were chosen via an educated guess. $P_{i n}$, however, was held initially at 130 bar in order to illustrate once more the significant impact that it has when moving from the first to the second iteration.

Table 2: Base values for tested design variables in Case $2 a$

\begin{tabular}{|c|c|c|c|c|}
\hline Parameter & $\mathbf{1}^{\text {st }}$ Iteration & $\mathbf{2}^{\text {nd }}$ Iteration & $\mathbf{3}^{\text {rd }}$ Iteration & Units \\
\hline $\mathrm{m}_{1 \mathrm{v}}$ & 0.19 & 0.19 & 0.19 & \\
\hline $\mathrm{P}_{1 \mathrm{v}}$ & 20 & 18 & 19 & bar \\
\hline $\mathrm{P}_{1}$ & 12.5 & 14 & 14 & bar \\
\hline $\mathrm{P}_{2}$ & 5 & 4.2 & 5 & bar \\
\hline $\mathrm{P}_{\text {in }}$ & 130 & 120 & 123 & bar \\
\hline $\mathrm{P}_{0}$ & 90 & 88 & 90 & bar \\
\hline
\end{tabular}

Figure 16 shows the sensitivity analysis results for $m_{1 v}$. The behavior is very similar to that observed in case 1 . On this plot, however, one can better see the local minimum that takes place at a low flow rate fraction around 0.035 . Thus, drawing away steam from the HP steam turbine is only advantageous after drawing away a mass fraction of at least 0.075 .

The results for $P_{1 v}$ adjustments are shown in Figure 17. The discontinuity on the left side for each of the iterations represents one or both of the reheaters reaching a pinch point and violating the $10^{\circ} \mathrm{C}$ approach temperature. For this reason, the base values for $P_{1 v}$ for each iteration were kept well to the

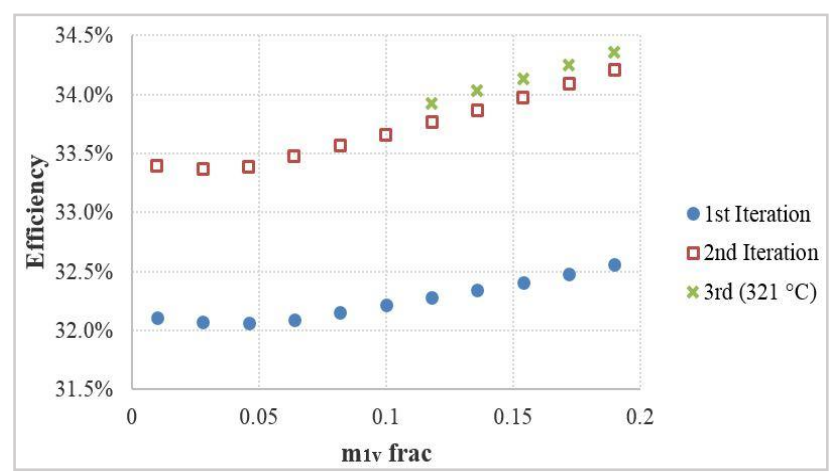

Figure 16: Efficiency vs. m1v for Case $2 a$

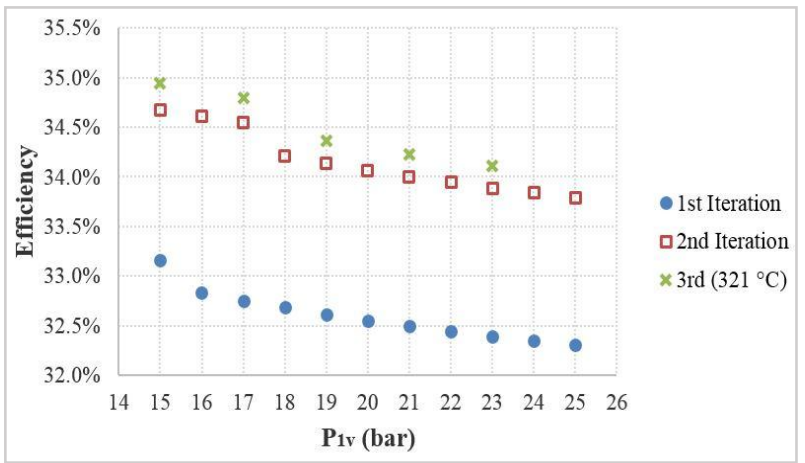

Figure 17: Efficiency vs. P1v for Case $2 a$

right of the pinch point values of $P_{1 v}$.

Figure 18 shows that, across the range of 10-15 bar, $P_{1}$ had little effect on the overall thermodynamic efficiency. The slope of these sensitivity analyses is still positive, so the base values for $P_{1}$ were kept at 
the higher end of this range. However, if $P_{1}$ was held too high, a pinch point was experienced in the first reheater.

Figure 19 shows that the outlet pressure for the IP steam turbine, $P_{2}$, experiences a maximum efficiency. The pressure at which this maximum was reached for each iteration varies. For the second iteration, the base value for $P_{2}$ was the local maximum from the first iteration. For the third iteration, the base value was the maximum from the second iteration.

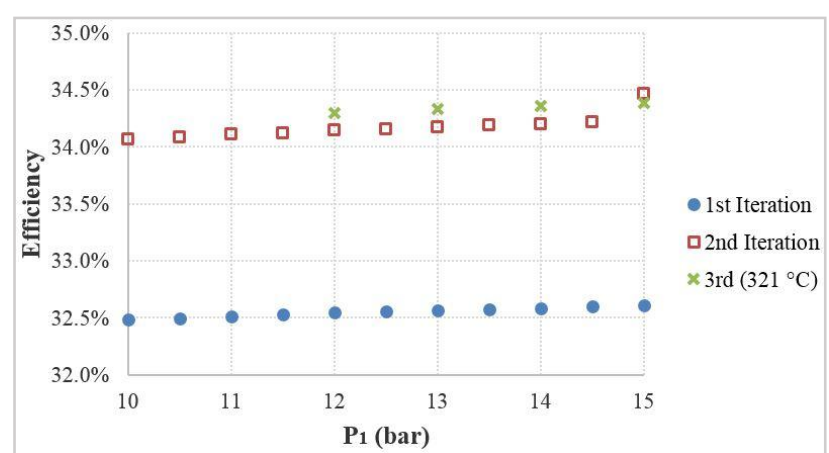

Figure 18: Efficiency vs. P1 for Case $2 a$

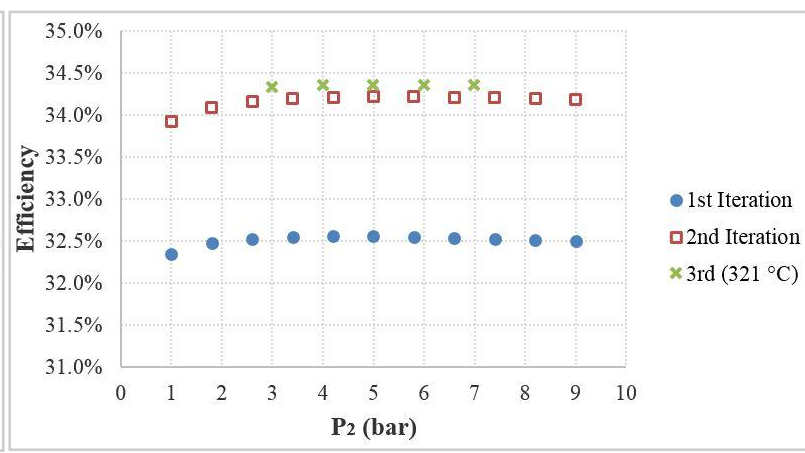

Figure 19: Efficiency vs. P2 for Case $2 a$

For the sensitivity analyses between $P_{\text {in }}$ and $P_{0}$, the values explored for $P_{\text {in }}$ were kept within 120 and 140 bar; the analyses for case 1 already showed that higher efficiencies are achieved at lower values of $P_{i n}$. Figure 20 shows the results of the sensitivity analyses for case $2 a$. Notable are the local maxima for the curves representing a $P_{i n}$ of 120,123 , and 130 bar. These maxima demonstrate that for a given $P_{i n}$, there comes a point when increasing $P_{0}$ even closer to $P_{\text {in }}$ no longer helps to improve the overall thermodynamic efficiency. The highest efficiency observed for case $2 a$ was from this third iteration at a $P_{\text {in }}$ of 123 bar and a $P_{0}$ of 92 bar; the efficiency achieved was $34.37 \%$.

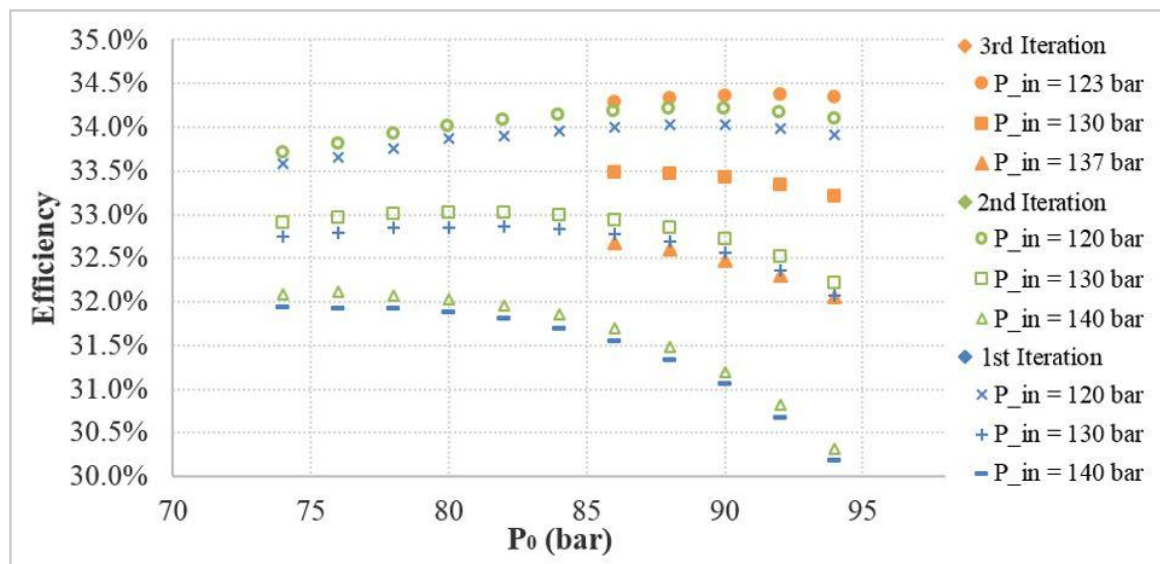

Figure 20: Efficiency vs. Pin and Po for Cas

\section{V.c. Case $\mathbf{2 b}$}

The sensitivity analyses for case design $2 b$ included the same six parameters as those for

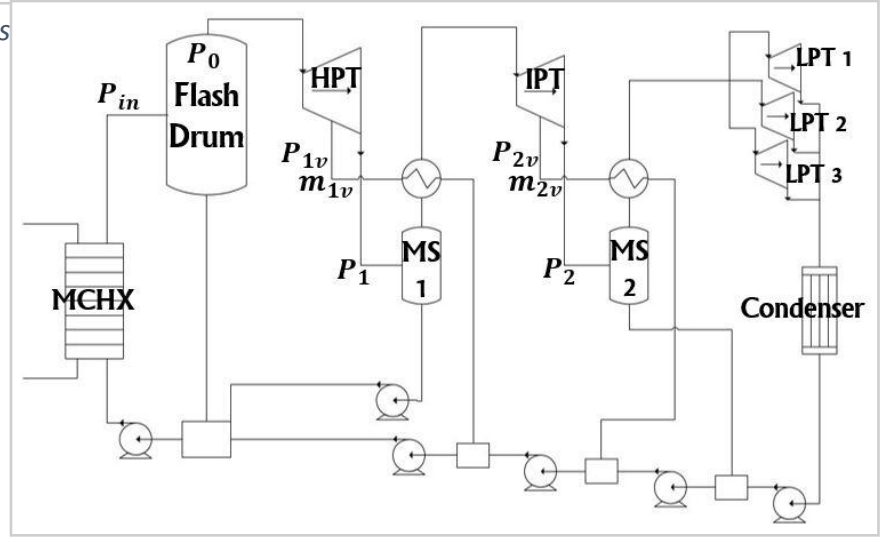


case 2a. Two additional parameters were analyzed, including the flow rate fraction and pressure of the steam drawn from the IP steam turbine, $m_{2 v}$ and $P_{2 v}$, respectively (see Figure 21).

The base values for these six parameters during the sensitivity analyses are found in Table 3Error! Reference source not found.. The starting values for the first iteration were chosen via an educated guess. $P_{\text {in }}$ again was held initially at 130 bar in order to show the significant impact that it has moving between the first and second iterations. The flow rate fractions $m_{1 v}$ and $m_{2 v}$ were only raised as high as 0.11 and 0.19 , because fractions greater than 0.15 and 0.3 , respectively, resulted in the reheating steams not condensing completely in the reheaters and entering the pumps as vapor.

Table 3: Base values for tested design variables in Case $2 b$

\begin{tabular}{|c|c|c|c|c|}
\hline Parameter & $\mathbf{1}^{\text {st }}$ Iteration & $\mathbf{2}^{\text {nd }}$ Iteration & $\mathbf{3}^{\text {rd }}$ Iteration & Units \\
\hline $\mathrm{m}_{1 \mathrm{v}}$ & 0.11 & 0.11 & 0.11 & \\
\hline $\mathrm{P}_{1 \mathrm{v}}$ & 20 & 20 & 20 & bar \\
\hline $\mathrm{P}_{1}$ & 15 & 15 & 15 & bar \\
\hline $\mathrm{m}_{2 \mathrm{v}}$ & 0.19 & 0.19 & 0.19 & \\
\hline $\mathrm{P}_{2 \mathrm{v}}$ & 10 & 8.2 & 8.8 & bar \\
\hline $\mathrm{P}_{2}$ & 5 & 6.2 & 5.6 & bar \\
\hline $\mathrm{P}_{\text {in }}$ & 130 & 120 & 123 & bar \\
\hline $\mathrm{P}_{0}$ & 88 & 90 & 88 & bar \\
\hline
\end{tabular}

The efficiencies obtained in these sensitivity analyses were higher than those obtained from cases 1 and 2a. During the second and third iterations, most of the higher efficiencies fell within the range of $35.5 \%$ to $36.0 \%$, as is seen in the following explanations.

Figure 22 shows the case $2 \mathrm{~b}$ sensitivity analyses for $m_{1 v}$. The behavior was the same as the first two cases; it is most efficient to increase $m_{1 v}$ as high as possible while still leaving a buffer to the fraction that will result in vapor entering the pumps downstream.

The results in Figure 23 show similar behavior to previous case designs as well. A $P_{1 v}$ of 20 bar was considered a sufficient distance from the discontinuities to the left for each of the iterations. Thus, $P_{1 v}$ was kept at this value throughout each iteration of the sensitivity analyses. 


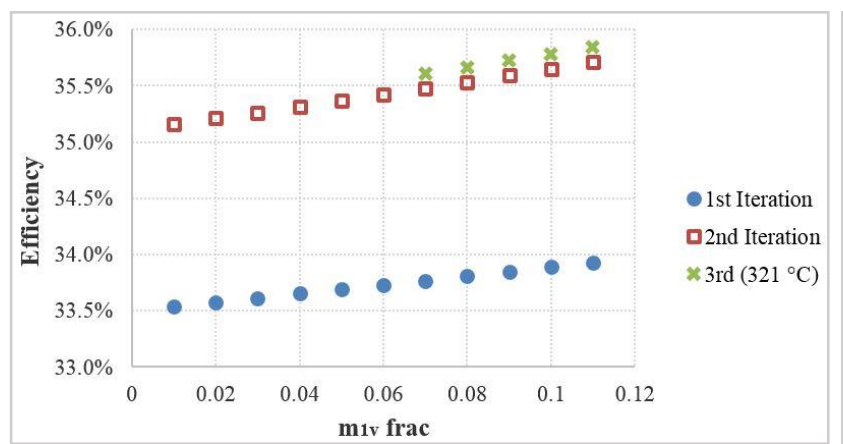

Figure 25: Efficiency vs. miv for Case $2 b$

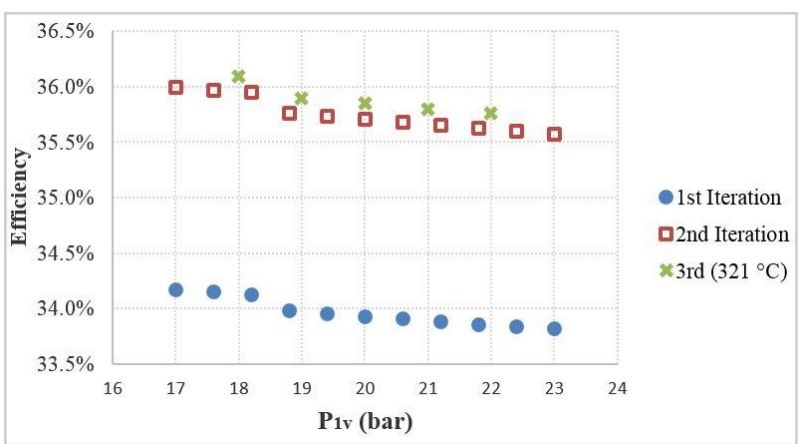

Figure 24: Efficiency vs. P1v for Case $2 b$

Figure 24 illustrates the results for each sensitivity analysis on $P_{1}$ coming out of the HP steam turbine. As before in cases 1 and 2a, a discontinuity lies to the right, representing $P_{1 v}$ and $P_{1}$ being too close in magnitude. This trend always resulted in a pinch point in the first reheater.

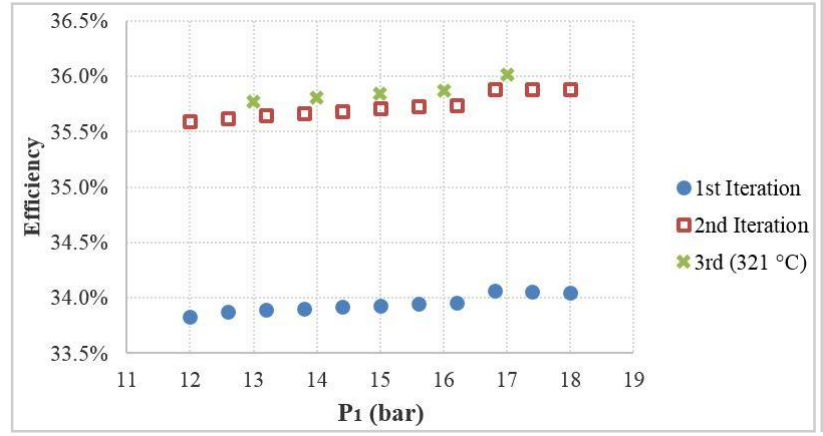

Figure 23: Efficiency vs. $P_{1}$ for Case $2 b$

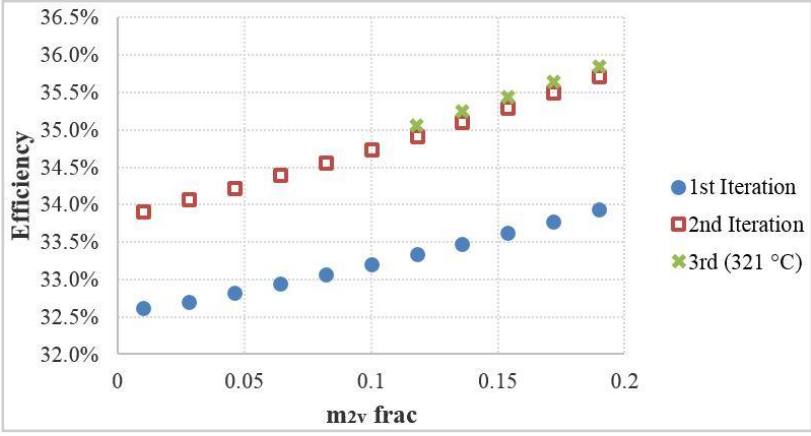

Figure 22: Efficiency vs. mav for Case $2 b$

In addition, $m_{2 v}$ was specifically evaluated with respect to its impact on efficiency. The sensitivity analyses for this variable indicated that its behavior is very similar to that of $m_{1 v}$. Figure 25 shows a monotonically increasing slope in efficiency with an increase in $m_{2 v}$. Again, the sensitivity analyses were bounded by a $m_{2 v}$ value of 0.19 , because values significantly higher than this resulted in pinch points in the reheater and water vapor inside the pumps.

Figure 26 shows the behavior of $P_{2 v}$, which acts much as $P_{1 v}$ does, with a negative slope in efficiency and discontinuities to the left. During the second and third sensitivity analyses, the base value for $P_{2 v}$ was held between 8 and 9 bar, keeping it away from the discontinuities representing pinch points due to proximity with $P_{2}$ coming out of the IP steam turbine.

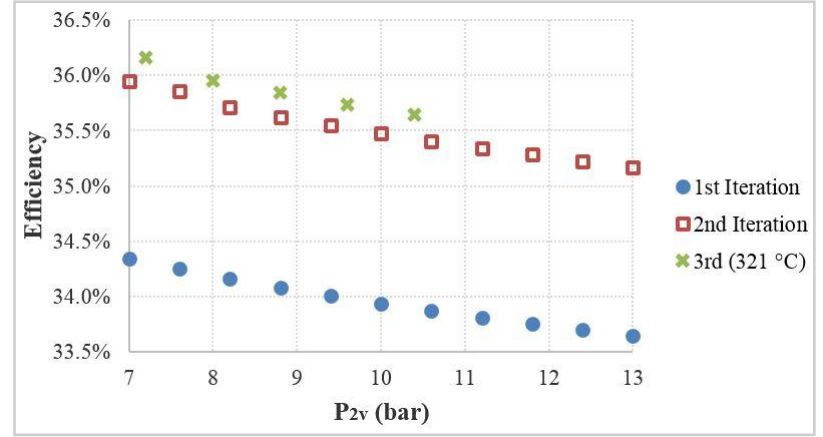

Figure 27: Efficiency vs. P2v for Case $2 b$

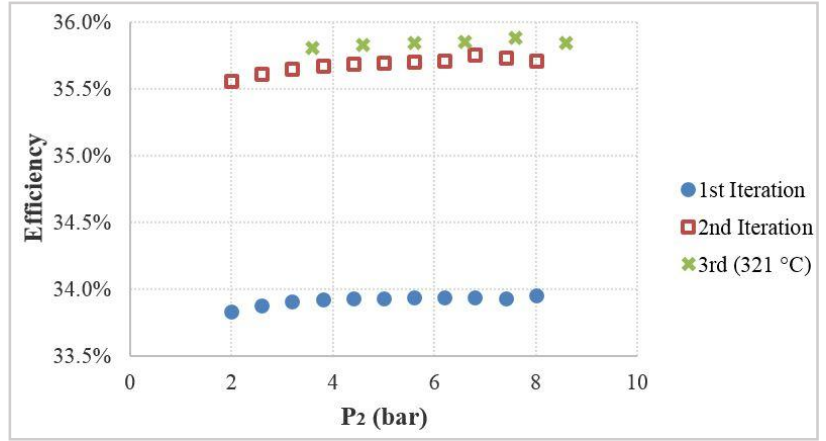

Figure 26: Efficiency vs. $P_{2}$ from Case $2 b$ 
$P_{2}$ also behaved in case $2 \mathrm{~b}$ just as it did in case $2 \mathrm{a}$. Figure 27 shows slight positive slopes in efficiency. The discontinuities on the right are not as prominent in the figure, though they are present. The base value for $P_{2}$ was changed from 5 to 6.2 to 5.6 bar in the respective iterations in order to stay a safe distrance from causing the pinch point in the second reheater.

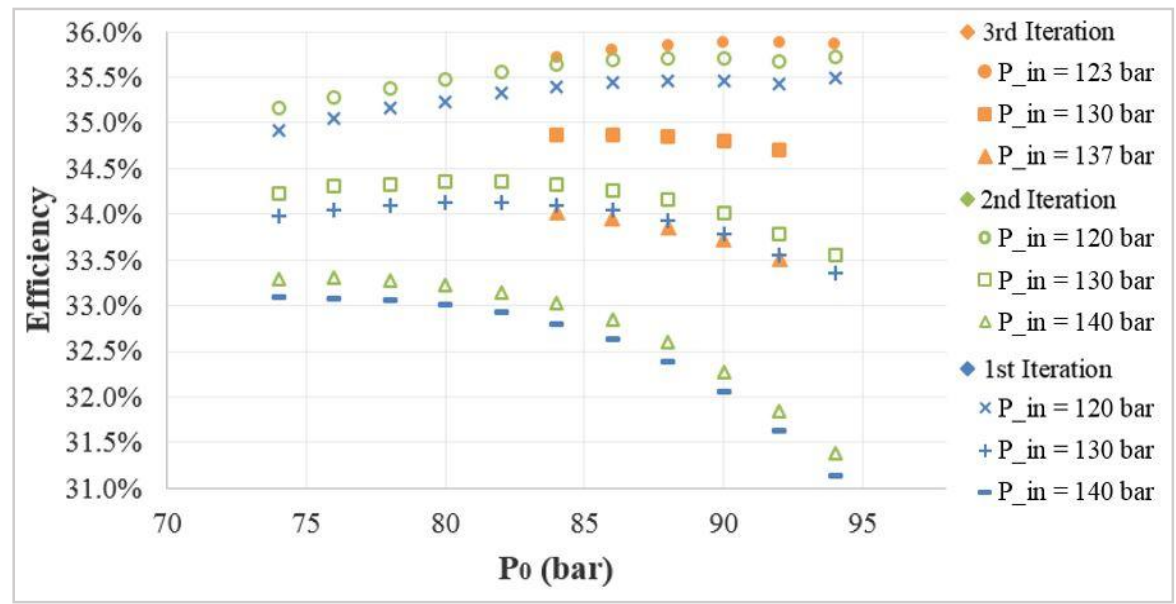

Figure 28: Efficiency vs. Pin and Po for Case $2 b$

For case $2 \mathrm{~b}$, the same values of $P_{\text {in }}$ and $P_{0}$ were explored as in case $2 \mathrm{a}$. The results are found in Figure 28. Similar behaviors were observed in case $2 \mathrm{~b}$ as before. The lower $P_{i n}$, the higher the overall thermodynamic efficiency. At its peak, the efficiency was $35.8821 \%$, at a $T_{\text {in }}$ of $321^{\circ} \mathrm{C}$, a $P_{\text {in }}$ of $123 \mathrm{bar}$, and a $P_{0}$ of 92 bar. This efficiency was the highest seen in any of the case designs.

\section{Results/Comparisons}

For the flash drum Rankine cycle, each case design was optimized through manipulation of key design parameters, and an absolute maximum overall thermodynamic efficiency was obtained. Error!

Reference source not found. shows these values, including the corresponding maximum efficiencies achieved. Note that the maximum efficiency for each case was achieved during the third iteration, when $T_{i n}$ going into the flash drum was allowed to increase to $321^{\circ} \mathrm{C}$. If allowing the temperature to rise to this level is deemed unsafe in the MCHX, then $T_{i n, \max }$ would be limited to $319^{\circ} \mathrm{C}$. In this case, Error! Reference source not found. shows the optimal parameter values assuming that $T_{i n}$ is $319^{\circ} \mathrm{C}$. The maximum efficiencies for each case are lower than their $321^{\circ} \mathrm{C}$ counterparts. However, the values in Error! Reference source not found. represent only two iterations of sensitivity analyses, where the values in Error! Reference source not found. were obtained after the third iteration.

Table 4: Optimal parameter values and efficiencies for each case (after 3 iterations, $\operatorname{Tin}=321^{\circ} \mathrm{C}$ )

\begin{tabular}{|c|c|c|c|c|}
\hline Parameter & Case 1 & Case 2a & Case 2b & Units \\
\hline $\mathrm{m}_{1 \mathrm{v}}$ & 0.19 & 0.19 & 0.11 & \\
\hline $\mathrm{P}_{1 \mathrm{v}}$ & 10 & 19 & 20 & bar \\
\hline $\mathrm{P}_{1}$ & 6.6 & 14 & 15 & bar \\
\hline $\mathrm{m}_{2 \mathrm{v}}$ & - & - & 0.19 & \\
\hline $\mathrm{P}_{2 \mathrm{v}}$ & - & - & 8.8 & bar \\
\hline $\mathrm{P}_{2}$ & - & 5 & 5.6 & bar \\
\hline $\mathrm{P}_{3}$ & 0.086 & 0.086 & 0.086 & bar \\
\hline
\end{tabular}




\begin{tabular}{|c|c|c|c|c|}
\hline $\mathrm{T}_{\text {in }}$ & 321 & 321 & 321 & ${ }^{\circ} \mathrm{C}$ \\
\hline $\mathrm{P}_{\text {in }}$ & 123 & 123 & 123 & bar \\
\hline $\mathrm{P}_{0}$ & 92 & 92 & 92 & bar \\
\hline$\eta_{\max }$ & 34.97 & 34.37 & 35.882 & $\%$ \\
\hline
\end{tabular}

Table 5: Optimal parameter values and efficiencies for each case (after 2 iterations, $\operatorname{Tin}=319^{\circ} \mathrm{C}$ )

\begin{tabular}{|c|c|c|c|c|}
\hline Parameter & Case 1 & Case 2a & Case 2b & Units \\
\hline $\mathrm{m}_{1 \mathrm{v}}$ & 0.19 & 0.19 & 0.11 & \\
\hline $\mathrm{P}_{1 \mathrm{v}}$ & 10 & 18 & 20 & bar \\
\hline $\mathrm{P}_{1}$ & 6.6 & 14 & 15 & bar \\
\hline $\mathrm{m}_{2 \mathrm{v}}$ & - & - & 0.19 & \\
\hline $\mathrm{P}_{2 \mathrm{v}}$ & - & - & 8.2 & bar \\
\hline $\mathrm{P}_{2}$ & - & 4.2 & 6.2 & bar \\
\hline $\mathrm{P}_{3}$ & 0.086 & 0.086 & 0.086 & bar \\
\hline $\mathrm{T}_{\text {in }}$ & 319 & 319 & 319 & ${ }^{\circ} \mathrm{C}$ \\
\hline $\mathrm{P}_{\text {in }}$ & 120 & 120 & 120 & bar \\
\hline $\mathrm{P}_{0}$ & 90 & 90 & 88 & bar \\
\hline$\eta_{\max }$ & 34.733 & 34.207 & 35.713 & $\%$ \\
\hline
\end{tabular}

No matter which $T_{\text {in }}$ assumption is used, case design $2 \mathrm{~b}$ consistently obtained the higher overall thermodynamic efficiency of the three cases, followed by case 1 and then case $2 a$. However, case $2 b$ requires the most capital equipment. Further economic analysis would clarify the cost-weighted differences between each case and whether added capital equipment and cost is worth the extra overall efficiency of the power conversion cycle. The final optimized thermodynamic efficiency of the most likely case, case $2 \mathrm{~b}$, with a $\mathrm{MCHX}$ outlet temperature of $319^{\circ} \mathrm{C}$ is $35.71 \%$, which is very close to the $\mathrm{I}^{2} \mathrm{~S}$ LWR project stretch-goal efficiency $36 \%$. The associated assumed values, system parameters, and component properties are reported in Error! Reference source not found..

\section{Conclusions}

The I'S-LWR must be capable of competing economically with currently operating nuclear power plants, or there will be no incentive for a vendor and operator to license and build the plant. In part, this means that the I'S-LWR must have an overall net thermodynamic efficiency comparable to current light water reactor power stations. The base PCS integrated with the $I^{2} S$-LWR is a modified flash-drum Rankine cycle. With this cycle, the $I^{2} S$-LWR can achieve a thermodynamic efficiency of nearly $36 \%$, which is the stretch goal established by the I²S-LWR design team.

Thus, the $I^{2} S-L W R$ is capable of achieving efficiencies that are either comparable to or greater than those currently achievable for operating nuclear power plants, indicating that it is possible for the $I^{2} S$-LWR to be economically competitive with current LWR nuclear power plants.

\section{Acknowledgments}

This research was performed through the help of funding received from the DOE Office of Nuclear Energy's Nuclear Energy University Programs (NEUP) under NEUP Project 12-4733, I2S-TR-13-01, (October 2013). 


\section{References}

1. S. Ansolabehere et al., "The Future of Nuclear Power An Interdisciplinary MIT Study", ISBN 0-61512420-8, Massachusetts Institute of Technology, 2003.

2. M. J Memmott, A. Manera "The use of Flashing Drums and Microchannel Heat Exchangers to Generate Steam in Large Integral Light Water Reactors", Nuclear Technology, Vol 191, Pg. 199-212, 2015.

3. L. Honorio et al., "Efficiency in Electricity Generation", EURELECTRIC "Preservation of Resources" working group, Brussels, Belgium, July, 2013.

4. S. I. Attia, "The Influence of Condenser Cooling Water Temperature on the Thermal Efficiency of a Nuclear Power Plant", Annals of Nuclear Energy, Vol. 80, Pg. 371-387, Jun 2015.

5. S. C. Gulen, R. W. Smith, "Second Law Efficiency of the Rankine Bottoming Cycle of a Combined Cycle Power Plant", Journal of Engineering for Gas Turbines and Power-Transactions of the ASME, Vol. 132, Issue 1, Pg. 011801, 2010.

6. R. S. Murugan, P. M. V. Subbarao, "Efficiency Enhancement in a Rankine Cycle Power Plant: Combined Cycle Approach", Proceedings of the Institution of Mechanical Engineers Part A-Journal of Power and Energy, Vol. 222, Issue A8, Pg. 753-760, 2008.

7. J. Siviter, A. Montecuccco, A. R. Knox, "Rankine Cycle Efficiency Gain Using Thermoelectric Heat Pumps", Applied Energy, Vol. 140, Pg. 161-170, Feb 2015.

8. A. Zandian, M. Ashjaee, "The Thermal Efficiency Improvement of a Steam Rankine Cycle by Innovative Design of a Hybrid Cooling Tower and a Solar Chimney Concept", Renewable Energy, Vol. 51, Pg. 465-473., Mar 2013.

9. World Nuclear Association, Nuclear Power Reactors, extracted 7/30/15, http://www.worldnuclear.org/info/Nuclear-Fuel-Cycle/Power-Reactors/Nuclear-Power-Reactors/.

10. N. E. Todreas, M. Kazimi, "Nuclear Systems Volume 1: Thermal Hydraulic Fundamentals $2^{\text {nd }}$ edition", CRC Press, September, 2011.

11. Y. A. Cengal, J. M. Cimbala, "Fluid Mechanics Fundamentals and Applications $3^{\text {rd }}$ edition" McGraw Hill, New York, NY, 2014. 